REVISTA ANDALUZA DE ANTROPOLOGÍA.

NÚMERO 2: PATRIMONIO CULTURAL Y DERECHOS COLECTIVOS.

MARZO DE 2012

ISSN 2174-6796

[pp. 158-161]

http://dx.doi.org/10.12795/RAA.2012.i02.09

\title{
VERGARA DURÁN, RICARDO ADRIÁN (ed.) (2011). Vulnerabilidad en grandes ciudades de América Latina. Barranquilla: Universidad del Norte, 150 pp.
}

\author{
Francisco José Cuberos Gallardo \\ Universidad de Sevilla
}

A diferencia de otras regiones empobrecidas del mundo, América Latina presenta una elevada tasa de urbanización que ronda el 80\% (United Nations, 2009). La conformación de grandes y medianas urbes no sólo tuvo lugar de manera temprana en el subcontinente latinoamericano, sino que además se desarrolló allí con especial intensidad (Bähr y Mertins, 1995). En consecuencia, lo urbano adquiere hoy un renovado interés en la agenda política y científica de la región. El crecimiento vertiginoso de las formas de pobreza urbana en las ciudades mexicanas, argentinas o brasileñas; el aumento de la inseguridad y la presencia del crimen organizado en las urbes de países como México y Colombia; o el impacto medioambiental de megalópolis como Sao Paulo, México D.F. o Buenos Aires se encuentran ya consolidados en el imaginario de la región que se maneja tanto dentro como fuera de ella. La propia idea de América Latina se encuentra crecientemente vinculada a una serie de riesgos que afectan especialmente a la población de sus ciudades.

Bajo el título Vulnerabilidad en grandes ciudades de América Latina, encontramos una compilación de artículos que abordan de manera poliédrica las múltiples y complejas manifestaciones de la vulnerabilidad en el medio urbano latinoamericano. Nueve especialistas de diferentes países se acercan al fenómeno de la vulnerabilidad en sus 
propias ciudades, ofreciendo al lector un conjunto rico y diverso de estudios de caso. Bajo la coordinación del antropólogo colombiano Ricardo Adrián Vergara Durán, geógrafos y arquitectos unen sus esfuerzos para analizar los riesgos que atraviesan la vida cotidiana de ciudades tan diferentes como Bogotá, Caracas, La Habana o San Miguel de Tucumán. La obra responde a un encargo de la Universidad del Norte (Colombia) y cuenta con el apoyo económico de la Red Científica Alemana Latinoamericana (ReCALL). El resultado nos permite constatar las ventajas del método etnográfico y su creciente reconocimiento desde fuera de la propia Antropología.

Abre el libro el propio Ricardo A. Vergara Durán, con un capítulo introductorio que sirve para ubicar la actualidad del debate sobre las nuevas formas de vulnerabilidad en América Latina. La novedad de esta vulnerabilidad, según el autor, radica fundamentalmente en una ampliación desde lo físico natural hacia lo político y socioeconómico (p.1). Partiendo de la definición que Karlos Pérez de Armiño hace de la vulnerabilidad como "el nivel de riesgo que afronta una familia o individuo a perder la vida, propiedades, bienes y su sistema de sustento ante una posible catástrofe" (1999), el autor propone repensar el riesgo como una contingencia cotidiana. En la ciudad latinoamericana la vulnerabilidad ha dejado de ser una disfunción eventual para ser parte estructurante de la vida social. Más que una amenaza externa, el riesgo es redefinido como parte del orden instituido. Un orden sobredeterminado por la triple crisis económica, socio-política y ambiental que envuelve la actualidad latinoamericana.

Laciudad, queoriginariamentefuesecreada para reducirycontrolar los peligros delentorno (p.6), se torna un contexto contenedor y generador de peligros. La propia exposición al peligro se convierte en rasgo definitorio de la vida en la ciudad. El objetivo último de esta obra es ilustrar, de forma original aunque algo desordenada, la diferente naturaleza de esos peligros. Salvo la aportación de Gürtens Mertins, que discurre teóricamente sobre la articulación de los problemas de vulnerabilidad, informalidad y gobernabilidad en la región, todos los artículos versan sobre riesgos específicos que son contextualizados en ciudades concretas. Las políticas de crecimiento urbano son analizadas en los casos de Caracas y San Miguel de Tucumán; la vivienda es problematizada en trabajos sobre La Habana y Manizales; los casos de Cali y Barranquilla sirven para reflexionar sobre la apropiación social del patrimonio y su defensa; y una urbanización pirata de Soacha es repensada desde la lógica de los inmigrantes llegados del medio rural. A pesar de la calidad desigual de los diferentes artículos, la obra ofrece en su conjunto material de interés para el lector general y para el antropólogo en particular.

La mayor parte de los autores recogen en el concepto de vulnerabilidad su dimensión cultural, y por tanto la forma en que es vivida por la población estudiada. Esto permite dar cuenta de las estrategias de resistencia a la vulnerabilidad que la población despliega. El capítulo de Francisco Javier Franco Silva es especialmente interesante en este punto. 
En él se traza un recorrido etnográfico a lo largo de la historia de una "urbanización pirata", nombre que reciben en Colombia las "fragmentaciones ilegales de terrenos que no cumplen las reglamentaciones de los organismos de planeación y carecen de servicios de infraestructuras y de servicios sociales y comunitarios" (p.13). Este tipo de vecindarios, conocidos como favelas en Brasil o villas miseria en Argentina, aparece como un rasgo idiosincrático del proceso de urbanización acelerada del subcontinente. Sin embargo, su abordaje en la vida política o mediática suele presentar a los habitantes de estos barrios como víctimas incapaces o bien como marginales de vocación. El texto de Franco Silva recoge de primera mano la estrategia de estas personas, y desde ahí reconstruye el sentido de una urbanización pirata en la que desde fuera sólo se reconoce pobreza y violencia.

La obra contiene así, como ventaja destacable, una sensibilidad a la singularidad de cada ciudad y un interés por los procesos históricos que la explican. En este sentido, los casos de estudio no son presentados como meros epifenómenos de tendencias globales, sino que -aun constatando la existencia de esas tendencias- son remitidos a la Historia de cada ciudad. La mayor parte de los autores contextualizan los datos que presentan a través de recorridos históricos, que permiten al lector entender la evolución seguida por los acontecimientos hasta el momento actual. Es el caso de Pablo Paolasso, Matilde Malizia y Fernando Longhi, cuando ilustran el proceso de crecimiento de San Miguel de Tucumán y los cambios que éste ha llevado aparejado en la re-ordenación de los circuitos económicos y las desigualdades sociales.

Un punto débil en algunos de los artículos es la persistencia de una concepción desarrollista del urbanismo, que aboga por un modelo único de ciudad y que ignora la perspectiva de los sujetos estudiados. Es el caso de Orestes Sardiñas Gómez y su análisis sobre las ciudadelas de La Habana. Tras constatar la precariedad arquitectónica de este tipo de vivienda, equiparable a los corrales de vecinos andaluces, la identifica como un factor de vulnerabilidad y termina abogando expresamente por su erradicación. En este artículo, y en algún otro, pasan desapercibidos los discursos de los habitantes de las ciudadelas, y especialmente las estrategias con que estos pueden intentar -y quizás lograr- hacer de ese modelo de vivienda un eje de resistencia a la vulnerabilidad. En contraste con otros artículos de la misma obra, aquí la mirada antropológica brilla por su ausencia.

El trabajo compilado por Ricardo A. Vergara Durán nos reporta una interesante diversidad de miradas sobre la vulnerabilidad propia de las ciudades latinoamericanas, si bien tales miradas son desiguales en sus logros. El libro en su conjunto nos acerca a las particularidades de varias ciudades y nos ayuda a entenderlas en sus respectivos contextos. Se logra en todo caso el objetivo de acercar al lector datos de primera mano sobre la problemática peculiar de distintas ciudades. Los datos aparecen conveniente contextualizados y nos permiten entender un poco mejor los riesgos que tejen la actualidad del medio urbano latinoamericano. 


\section{Referencias bibliográficas}

BÄHR, Jürgen y MERTINS, Günter (1995) Die lateinamerikanische GrossStadt. Verstädterungsprozesse und Stadtstrukturen. Darmstadt: Wissenschaftliche Buchgesselschaft.

PÉREZ DE ARMIÑO, Karlos (1999) "Vulnerabilidad y desastres. Causas estructurales y procesos de la crisis de África", Cuadernos de Trabajo de HEGOA, no 24. Bilbao: Universidad del País Vasco.

UNITED NATIONS (2009) World Urbanization Prospects. The 2008 Revision. New York: United Nations. 